\title{
Comparative Study Between Vaginal Natural Progesterone and Oral Dydrogesterone in Prevention of Red Degeneration of Uterine Fibroid in Pregnancy
} Original Article

Tarek A. Karkour, Tamer M. Abdeldaiem, Nermin M. Hefila, Sarah M. Elghareeb

Department of Obstetrics and Gynecology, Faculty of Medicine, Alexandria University, Egypt

\begin{abstract}
Background: Uterine leiomyomas are highly prevalent benign monoclonal tumors, arising from the smooth muscle of the myometrium; The most serious complication of uterine fibroids; is red degeneration that causes severe pain, and may lead to preterm labour, miscarriage, fetal and maternal morbidity and mortality.

Aim: This work was designed to compare between the effect of vaginal natural MP and oral dydrogesterone in prevention of red degeneration of uterine fibroid during pregnancy.

Material and Methods: Patients were recruited from El-Shatby Maternity University Hospital. They were 50 pregnant females, diagnosed having a uterine fibroid more than $3 \mathrm{~cm}$ in size then there were divided into two groups, group (A): twenty five treated by vaginal natural Progesterone, group (B): twenty five treated by oral Dydrogesterone.All patients at 14-15 weeks of gestational age underwent complete history taking, clinical examination and ultrasound examination for mean gestational age and assessment of the type and uterine fibroid.

Results: Results showed that there were no statistical significant differences as regards age, obstetric history (gravidity and parity), number, Site, grade and size of the fibroid. There was a significant difference between the two studied groups, regarding the acute abdominal pain, it occurred to only 3 cases (12\%) in group (A), versus to 16 cases (64\%) in group (B). Regarding occurrence of red degeneration, it occurred only to 3 cases (12\%) in group (A), while in group (B) it occurred to 15 cases $(60 \%)$.

Conclusion : Vaginal natural micronized progesterone is more effective than oral dydrogesterone in prevention of red degeneration of uterine fibroids with fewer complications like acute abdominal pain and preterm labour
\end{abstract}

Key Words: Oral Dydrogesterone, pregnancy, red degeneration of uterine fibroid, vaginal natural progesterone

Received: 10 February 2020, Accepted: 06 December 2020

Corresponding Author: Nermeen Mohamed Hefila, Department of Obstetrics and Gynecology, Faculty of Medicine, Alexandria University, Egypt, Tel.: 01008020855, E-mail: nermeenptsbasem81@gmail.com

ISSN: 2090-7265, May 2021, Vol.11, No. 2

\section{INTRODUCTION}

Uterine fibroids(myomas or leiyomymas) are the most common benign tumor of the female genital tract ${ }^{[1]}$. They are monoclonal tumors of the uterine smooth muscle cells and consist of large amounts of extracellular matrix that contain collagen, fibronectin, and proteoglycan ${ }^{[2]}$. Despite the fact that their cause is still unknown, yet there is considerable evidence that estrogens and progestogens proliferate tumor growth, ${ }^{[3]}$ as the fibroids rarely appear before menarche and regress after menopause $\mathrm{e}^{[4]}$.

Most fibroids are asymptomatic. However, severe localized abdominal pain can occur if a fibroid undergoes so-called "red degeneration," torsion(seen most commonly with a pedunculated subserosal fibroid). Pain is the most common complication of fibroids in pregnancy, and is seen most often during the second and third trimesters of pregnancy. ${ }^{[5]}$ Red degeneration is a hemorrhagic infarction of the uterine leiomyoma, which is a well-known complication, especially during pregnancy. It occurs in $8 \%$ of tumors complicating pregnancy, although the prevalence is about $3 \%$ of all uterine leiomyoma ${ }^{[6]}$.

It causes severe pain; these women should be treated conservatively as any surgical procedure during the pregnancy can result in preterm delivery and fetal loss. Women with fibroids who get pregnant should be allowed to continue pregnancy and all efforts made to make sure they have normal hemoglobin at delivery. Delivery should be planned to ensure the correct route is chosen ${ }^{[7]}$.

Progesterone is an essential steroid hormone in the process of reproduction. It modulates the immune response of the mother to prevent rejection of the embryo, and enhances uterine quiescence and suppresses uterine contractions $^{[8]}$.

Oral administration guarantees optimal compliance by patients but shows many disadvantages; this route also results in side effects such as nausea, headache and sleepiness. The vaginal route results in higher 
concentrations in the uterus but does not reach high and constant blood levels ${ }^{[9]}$.

Dydrogestrone is a retroprogesterone with good oral bioavailability that has a biological active metabolite of progesterone, which has an anti-estrogenic effect on the endometrium producing a secretory transformation ${ }^{[10]}$. It also positively affects its selectivity, while oral natural progesterone is less selective, existing in different conformations that more easily bind to different receptors $^{[11]}$. Fibroid pain during pregnancy is usually managed conservatively by bed rest, hydration, and analgesics ${ }^{[5]}$. Definitive treatment being postponed until postpartum $^{[12]}$.

\section{AIM OF THE WORK}

The aim of this study was to compare the effect of vaginal natural Progesterone versus oral Dydrogesterone in preventing occurrence of red degeneration complication in uterine fibroid during pregnancy.

\section{PATIENTS AND METHODS}

This study included 50 pregnant females diagnosed having a uterine fibroid more than $3 \mathrm{~cm}$ in size, presented to Elshatby maternity university hospitals. They were divided into two groups : Group A included 25 pregnant females treated by vaginal natural Progesterone [200 mg/ day from 14- 34 weeks gestation] and group B included 25 pregnant females treated by oral Dydrogesterone [20 mg/ day from 14-34 weeks gestation].

Inclusion criteria : Pregnant female diagnosed having a uterine fibroid more than $3 \mathrm{~cm}$ by ultrasound.

Exclusion criteria : A Uterine fibroid less than 3 $\mathrm{cm}$ in size. Contraindication to Progesterone (as presence of hypersensitivity). Patient diagnosed having a uterine fibroid complicated by red degeneration in the current pregnancy. Pregnant females with gestational age $>34$ weeks. Pregnant female with high risk medical condition as DM, PET .

All patients signed a full informed consent and were subjected to history taking, general examination and transvaginal or abdominal ultrasonography to assess type and size of the uterine fibroid and exclude any complications of fibroid before the administration of vaginal natural progesterone or oral dydrogesterone as well as confirming the gestational age and assess fetal wellbeing.

Moreover, administration of vaginal natural Progesterone for group A [200mg /day from 14- 34 weeks gestation] and oral Dydrogesterone for group B [20 mg per day from 14-34 weeks gestation] as well as to estimate incidence of red degeneration, all patients will undergo every month till delivery; physical examination regarding pain as symptom and tenderness as a sign over the site uterine fibroid and abdominal ultrasound imaging showing a heterogeneous echogenic pattern or cystic changes of the uterine fibroid.

\section{RESULTS}

Table 1 showed comparison between the two studied groups according to age, obstetric history and gestational age at start and at end of treatment. There was no significant difference between the two groups regarding age, gravidity, parity and start of treatment $(p>0.05)$. Regarding to the start of treatment, statistically significant differences were noted between the two studied groups $(p<0.05)$.

Table 2 showed comparison between the two studied groups according to fibroid Number. grade and size of the fibroid. There was no significant difference between the two studied groups regarding number of fibroids, grade and size of the fibroid $(p>0.05)$.

Table 3 showed comparison between the two studied groups according to Fibroid Site and occurrence of acute abdominal pain. There was no significant difference between the two groups regarding fibroid site $(p>0.05)$, while regarding occurrence of acute abdominal pain, statistically significant differences were noted between the two studied groups. $(p<0.05)$

Table 4 showed comparison between the two studied groups according to gestational age at delivery, Red degeneration occurrence and labour onset. Regarding gestational age at delivery, statistically significant differences were noted between the two studied groups $(p<0.05)$. There was statistically significant differences were noted between the two studied groups regarding to labour onset $(p<0.05)$. 
Table 1: Comparison between the two studied groups according to age, obstetric history and gestational age at start and end of treatment

\begin{tabular}{lcccc}
\hline & $\begin{array}{c}\text { Group A } \\
(\mathrm{n}=25)\end{array}$ & $\begin{array}{c}\text { Group B } \\
(\mathrm{n}=25)\end{array}$ & $\mathrm{t}$ & 0.724 \\
\hline Age (years) & $27.60 \pm 4.37$ & $28.52 \pm 4.61$ & 0.472 \\
Gravidity & $2.40 \pm 1.0$ & $2.44 \pm 1.16$ & 311.00 & 0.976 \\
Parity & $1.0 \pm 0.87$ & $0.88 \pm 0.83$ & 290.00 & 0.637 \\
G.A. Start of treatment (weeks) & $14.44 \pm 0.51$ & $14.40 \pm 0.50$ & 0.281 & 0.780 \\
G.A. End of treatment (weeks) & $31.92 \pm 4.70$ & $28.28 \pm 4.57$ & $2.777^{*}$ & $0.008^{*}$ \\
\hline
\end{tabular}

Table 2: Comparison between the two studied groups according to fibroid Number. grade and size of the fibroid

\begin{tabular}{|c|c|c|c|c|c|c|}
\hline & \multicolumn{2}{|c|}{$\begin{array}{l}\text { Group A } \\
(\mathrm{n}=25)\end{array}$} & \multicolumn{2}{|c|}{$\begin{array}{l}\text { Group B } \\
(\mathrm{n}=25)\end{array}$} & \multirow[t]{2}{*}{ Test of sig. } & \multirow[t]{2}{*}{$p$} \\
\hline & No. & $\%$ & No. & $\%$ & & \\
\hline \multicolumn{7}{|l|}{ Fibroid } \\
\hline 1 & 10 & 40.0 & 13 & 52.0 & \multirow{4}{*}{$\begin{array}{c}\chi^{2}= \\
1.063\end{array}$} & \multirow{4}{*}{$\begin{array}{l}{ }^{\mathrm{MC}} \mathrm{p}= \\
0.865\end{array}$} \\
\hline 2 & 10 & 40.0 & 8 & 32.0 & & \\
\hline 3 & 4 & 16.0 & 3 & 12.0 & & \\
\hline 4 & 1 & 4.0 & 1 & 4.0 & & \\
\hline Mean \pm SD & \multicolumn{2}{|c|}{$1.840 .85 \pm$} & \multicolumn{2}{|c|}{$1.680 .85 \pm$} & $\mathrm{U}=275.50$ & 0.437 \\
\hline Total fibroid number & \multicolumn{2}{|c|}{46} & \multicolumn{2}{|c|}{42} & & \\
\hline Grade & \multicolumn{2}{|c|}{$5.071 .34 \pm$} & \multicolumn{2}{|c|}{$5.261 .25 \pm$} & 895.50 & 0.546 \\
\hline Size $(\mathrm{cm})$ & \multicolumn{2}{|c|}{$5.132 .01 \pm$} & \multicolumn{2}{|c|}{$4.83 \pm 1.26$} & 962.0 & 0.973 \\
\hline
\end{tabular}

Table 3: Comparison between the two studied groups according to Fibroid Site and occurrence of acute abdominal pain

\begin{tabular}{|c|c|c|c|c|c|c|}
\hline & \multicolumn{2}{|c|}{$\begin{array}{l}\text { Group A } \\
(\mathrm{n}=46)\end{array}$} & \multicolumn{2}{|c|}{$\begin{array}{l}\text { Group B } \\
(\mathrm{n}=42)\end{array}$} & \multirow{2}{*}{$\chi^{2}$} & \multirow{2}{*}{$p$} \\
\hline & No. & $\%$ & No. & $\%$ & & \\
\hline \multicolumn{7}{|l|}{ Site } \\
\hline Post wall & 27 & 58.7 & 19 & 45.2 & & \\
\hline Ant wall & 13 & 28.3 & 16 & 38.1 & 1.600 & 0.449 \\
\hline Fundal & 6 & 13.0 & 7 & 16.7 & & \\
\hline \multicolumn{7}{|c|}{ Acute abdominal pain } \\
\hline Positive & 3 & 12.0 & 16 & 64.0 & $14.346^{*}$ & $<0.001^{*}$ \\
\hline Negative & 22 & 88.0 & 9 & 36.0 & & \\
\hline
\end{tabular}

Table 4: Comparison between the two studied groups according to gestational age at delivery and Red degeneration occurrence and laborer onset

\begin{tabular}{|c|c|c|c|c|c|c|}
\hline & \multicolumn{2}{|c|}{$\begin{array}{l}\text { Group A } \\
(\mathrm{n}=22)\end{array}$} & \multicolumn{2}{|c|}{$\begin{array}{c}\text { Group B } \\
(\mathrm{n}=22)\end{array}$} & $\mathrm{t}$ & $p$ \\
\hline Gestational age at delivery & \multicolumn{2}{|c|}{$38.36 \pm 2.04$} & \multicolumn{2}{|c|}{$36.86 \pm 2.05$} & $2.432^{*}$ & $0.019^{*}$ \\
\hline Outcome & No. & $\%$ & No. & $\%$ & $\chi^{2}$ & ${ }^{\mathrm{MC}} \mathrm{p}$ \\
\hline Red degeneration & 3 & 12.0 & 15 & 60.0 & & \\
\hline Miscarriage & 3 & 12.0 & 3 & 12.0 & $13.816^{*}$ & $0.001^{*}$ \\
\hline Successful & 19 & 76.0 & 7 & 28.0 & & \\
\hline \multicolumn{7}{|l|}{ Labour } \\
\hline Preterm & 1 & 4.5 & 8 & 36.4 & \multirow{2}{*}{$6.844^{*}$} & \multirow{2}{*}{0.021} \\
\hline Full term & 21 & 95.5 & 14 & 63.6 & & \\
\hline
\end{tabular}




\section{DISCUSSION}

Presence of myoma during pregnancy is a serious problem and of frequent clinical concern, as fibroid is commonly detected in reproduction age women in up to $50-60 \%{ }^{[13]}$ So careful monitoring of the patient is needed during antenatal, perinatal and postnatal period.

The tumor responds differently in individual pregnant women, it may grow, regress or remain unchanged in size. ${ }^{[14]}$ And have been implicated as a cause of adverse pregnancy outcome. According to leiomyoma size and location, it may causes preterm labour, PROM, IUGR, placental abruption, uterine dysfunction, obstructed labour, mal presentations, retained placenta, and post-partum hemorrhage ${ }^{[15,16]}$.

A well-known complication during the second half of pregnancy is red degeneration, ${ }^{[17]}$ which is acute focal abdominal pain caused by a hemorrhagic infarction leading to necrotic cysts formation in the uterine leiomyoma. ${ }^{[18]}$ Red degeneration occurs in $8 \%$ of tumors during pregnancy, ${ }^{[19,20]}$ causing severe pain, localized tenderness over the site of the fibroid and may be associated with nausea, vomiting, and mild fever ${ }^{[21]}$.

It can be diagnosed by abdominal ultrasound imaging showing a heterogeneous echogenic pattern or cystic changes of the uterine fibroid. Physical examination regarding pain as symptom and tenderness as a sign over the site of uterine fibroid.

Progesterone hormone is indispensable for the maintenance of pregnancy, also, it increases the blood flow in the vascular wall to the site of the myoma, ${ }^{[21]}$ because its receptors exhibit higher expression in fibroids compared with the adjacent myometrium ${ }^{[22,23]}$.

Progesteronesupplements are eithernatural progesterone or synthetic progesterone, Natural progesterone is like vaginal natural micronized progesterone. While, synthetic progesterone is like oral dydrogesterone.

Vaginal natural MP affects the uterus directly and absorbed quickly resulting in the highest uterine concentrations ${ }^{[24,25]}$ without general side effects and better bioavailability ${ }^{[26]}$.

Oral dydrogesterone is synthetic retroprogesterone. That structurally and pharmacologically similar to natural progesterone, with enhanced oral bioavailability ${ }^{[27]}$ and known for being higher selective progesterone receptor agonist than oral MP, at a dose 10-20 times lower than oral MP ${ }^{[28]}$

In the current study, the mean age in group A was $27.60 \pm 4.37$ years while in group B it was $28.52 \pm 4.61$ years. There was no significant difference between the two groups regarding age. Regarding obstetric history, number,
Site, grade and size of the fibroid there was no significant difference between the two groups.

According to the start of treatment, there was no significant difference between the two studied groups as both started at 14-15 weeks of gestation.

Only 3 cases (12\%), in group (A) suffered from acute abdominal pain, versus to 16 cases $(64 \%)$ in group (B) complained of it, significant difference was noted between the two studied groups. $(p=<0.001)$

Regarding labour onset; in group (A), only one case delivered preterm $(4.5 \%)$, While In group (B), 8 cases delivered preterm (36.4). There was significant difference between the two studied groups. $(p=0.021)$

In addition to the gestational age at the delivery, the mean in group (A) was $38.36 \pm 2.04$, while in group (B) was $36.86 \pm 2.05$. Statistically significant difference was noted between the two studied groups. $(p=0.019)$

Additionally, as expected the tried treatment ended in group B before group A to control complications as acute pain resulted from the aseptic necrobiosis by good hydration, injectable progesterone and analgesics. There was a significant difference between the two groups $(P=0.008)$

The present study shows that vaginal administration of MP in pregnant women with uterine fibroid results in significantly less occurrence of red degeneration, when compared with oral dydrogesterone $(P=0.001)$. Because in group (A) it occurred only in 3 cases (12\%), while in group (B) it occurred in 15 cases $(60 \%)$.

In light of the discussion above, the potential clinical benefits of vaginal natural progesterone supplementation appear large, whereas the oral dydrogesrterone seems small in comparison.

\section{CONCLUSION}

This study concluded that vaginal natural micronized progesterone is more effective than oral dydrogesterone in prevention of red degeneration of uterine fibroids with fewer complications like acute abdominal pain and preterm labour. Vaginal micronized progesterone $(200 \mathrm{mg}$ once daily) is effective and recommended to all pregnant cases with uterine fibroids.

\section{RECOMMENDATIONS}

Based on the results of this study, the following could be recommended conducting this study on a larger sample size of patients in multicenter to ensure these findings and confirm its clinical values. Vaginal MP is recommended for all pregnant cases with uterine fibroids. 


\section{CONFLICTS OF INTEREST}

There are no conflict of interests.

\section{REFERENCES}

1. Okolo S. Incidence, etiology and epidemiology of uterine fibroids. Best Pract Res Clin Obstet Gynaecol 2008;22(4):571-88

2. Khan AT, Shehmar M, Gupta JK. Uterine fibroids: current perspectives. Int $\mathrm{J}$ Womens Health 2014;6:95-114.

3. Kempson RL, Hendrickson MR. Smooth muscle, endometrial stromal, and mixed Müllerian tumors of the uterus. Mod Pathol 2000;13(3):328-42.

4. Zimmermann A, Bernuit D, Gerlinger C, Schaefers M, Geppert K. Prevalence, symptoms and management of uterine fibroids: an international internet-based survey of 21,746 women. BMC Womens Health 2012;12:6.

5. Lee HJ, Norwitz ER, Shaw J. Contemporary Management of Fibroids in Pregnanc. Rev Obstet Gynecol 2010;3(1):20-7.

6. Han SC, Kim MD, Jung DC, Lee M, Lee MS, Park SI, et al. Degeneration of leiomyoma in patients referred for uterine fibroid embolization: incidence, imaging features and clinical characteristics. Yonsei Med J 2013;54(1):215-9.

7. Simms-Stewart D, Fletcher H. Counselling patients with uterine fibroids: a review of the management and complications. Obstet Gynecol Int 2012;2012:539365.

8. Di Renzo Gc, Giardina I, Clerici G, Brillo E, Gerli S. Progesterone in normal and pathological pregnancy. Horm Mol Biol Clin Investig 2016;27(1):35-48.

9. Dante G, Vaccaro V, Facchinetti F. Use of progestagens during early pregnancy. Facts Views Vis Obgyn 2013;5(1):66-71.

10. Salehpour S, Tamimi M, Saharkhiz N. Comparison of oral dydrogesterone with suppository vaginal progesterone for luteal-phase support in in vitro fertilization (IVF): A randomized clinical trial. Iran J Reprod Med 2013;11(11):913-8.

11. Schindler AE. Progestational effects of dydrogesterone in vitro, in vivo and on the human endometrium. Maturitas 2009;65 Suppl 1:S3-11.
12. Sahana Gupta, Isaac T. Manyonda, Acute complications of fibroids. Best Pract Res Clin Obstet Gynaecol 2009;23(5):609-17.

13. Qidwai GI, Caughey AB, Jacoby AF. Obstetric outcomes in women with sonographically identified uterine leiomyomata. Obstet Gynecol 2006;107(2 Pt 1):376-82.

14. Shobhitha GL, Hima bindu P, Sireesha KV. Myoma Complicating Pregnancy A report of two cases. J Dent Med Sci 2015;14(4):33-6.

15. Ouyang DW, Economy KE, Norwitz ER. Obstetric complications of fibroids. Obstet Gynecol Clin North Am 2006;33(1):153-69.

16. Mason TC. Red degeneration of a leiomyoma masquerading as retained products of conception. J Natl Med Assoc 2002;94(2):124-6.

17. Patel B, Elguero S, Thakore S, Dahoud W, Bedaiwy M, Mesiano S. Role of nuclear progesterone receptor isoforms in uterine pathophysiology. Hum Reprod Update 2015;21(2):155-73

18. Nakai G, Yamada T, Hamada T, Atsukawa N, Tanaka Y, Yamamoto K, et al. Pathological findings of uterine tumors preoperatively diagnosed as red degeneration of leiomyoma by MRI. Abdom Radiol (NY) 2017;42(7):1825-31.

19. Han SC, Kim MD, Jung DC, Lee M, Lee MS, Park SI, et al. Degeneration of leiomyoma in patients referred for uterine fibroid embolization: incidence, imaging features and clinical characteristics. Yonsei Med J 2013;54(1):215-9.

20. Deveer M, Deveer R, Engin-Ustun Y, Sarikaya E, Akbaba E, Senturk B, et al. Comparison of pregnancy outcomes in different localizations of uterine fibroids. Clin Exp Obstet Gynecol 2012;39(4):516-8.

21. Hajek Z, Uhlir M. Micronized progesterone in the treatment of imminent necrosis of a myoma during pregnancy. Ultrasound changes during treatment. Ceska Gynekol 1999;64(3):189-92.

22. Brandon DD, Bethea CL, Strawn EY, Novy MJ, Burry KA, Harrington MS, et al. Progesterone receptor messenger ribonucleic acid and protein are overexpressed in human uterine leiomyomas. Am J Obstet Gynecol 1993;169(1):78-85.

23. Englund K, Blanck A, Gustavsson I, Lundkvist U, 
Sjoblom P, Norgren A, et al. Sex steroid receptors in human myometrium and fibroids: changes during the menstrual cycle and gonadotropin-releasing hormone treatment. J Clin Endocrinol Metab 1998;83(11):4092-6.

24. How HY, Sibai BM. Progesterone for the prevention of preterm birth: indications, when to initiate, efficacy and safety. Ther Clin Risk Manag 2009;5(1):55-64.

25. Cicinelli E, Schonauer LM, Galantino P, Matteo MG, Cassetta R, Pinto V. Mechanisms of uterine specificity of vaginal progesterone. Hum Reprod 2000;15 Suppl 1:159-65.
26. Levy T, Yairi Y, Bar-Hava I, Shalev J, Orvieto R, Ben-Rafael Z. Pharmacokinetics of the progesteronecontaining vaginal tablet and its use in assisted reproduction. Steroids 2000;65(10-11):645-9.

27. Schindler AE. Progestational effects of dydrogesterone in vitro, in vivo and on the human endometrium. Maturitas 2009;65 Suppl 1:S3-11.

28. Schindler AE, Campagnoli C, Druckmann R, Huber J, Pasqualini JR, Schweppe KW, et al. Classification and pharmacology of progestins. Maturitas 2003;46 Suppl 1:S7-s16. 